\title{
Comparison Between Deep Intracornual Artificial Insemination (DIAI) and Conventional Artificial Insemination (AI) Using low Concentration of Spermatozoa in Beef Cattle
}

\author{
Ciro Meirelles ${ }^{1}$, Luiz Ernandes Kozicki ${ }^{1 *}$, Romildo Romualdo Weiss ${ }^{2}$, Marcio Saporski \\ Segui $^{1}$, Antonio Souza ${ }^{3}$, Ivo Walter dos Santos ${ }^{2}$ and Jose Carlos dos Santos Breda ${ }^{4}$ \\ ${ }^{1}$ Veterinarian and Professor at the Pontifical University Catholic of Parana. ${ }^{2}$ Veterinarian and Professor at the \\ Federal University of Paraná ${ }^{3}$ Veterinarian - Vet-Maxi Maximization Livestock Ltd. ${ }^{4}$ Veterinary and Master's \\ Graduate Program in Animal Science
}

\begin{abstract}
This study aimed to compare the pregnancy rate using the conventional artificial insemination (AI) or deep intracornual artificial insemination (DIAI), with low number of spermatozoa (4.0 million sperm) in 270 Nelore cows. The animals were divided in two groups ( $G$ : G1 (135 cows) conventional AI was performed (=semen deposition in the uterine body) and in G2 (135 cows) to DIAI, in ipsilateral horn where the dominant follicle in the ovary had previously been detected, by ultrasound examinations. For both the methods, a single artificial insemination was carried out after visual estrus observation, checked three times a day (morning, afternoon and evening). The pregnancy diagnosis after 45 days was conducted by ultrasound. Results showed a better pregnancy rate in the DIAI group (67.4\% - p<0.01), when compared to conventional AI (48.8\%) with low spermatozoa concentration.
\end{abstract}

Key words: Deep intracornual artificial insemination, Beef cattle, Artificial insemination, Nelore cows

\section{INTRODUCTION}

The modernization and intensification of cattle production is a dynamic process including the improvement of the quality and quantity of animal products. Hunter and Greve (1998) reported that a better understanding of reproductive anatomy and physiology (transportation and survival of gametes), and others processes involved in fertilization, would allow to develop more efficient procedures for AI. There's no doubt about the benefits of semen deposition in the uterine body as compared to deposition in the cervix. However, there are doubts about the best location for the deposition of semen after the cervix (Lopez-Gatius 2000). According to Hawk et al. (1983), Larsson and Larsson (1985), Nelson (1987) and Seidel Jr et al. (1999) the deposition of semen near to the uterus-tubal junction could reduce the spermatic loss, either by the retrograde flow of uterine mucus, or by the phagocytosis during uterine migration. Hawk and Tanabe (1986) inseminated

\footnotetext{
* Author for correspondence: kozicki.1@ pucpr.br
} 
cows by the conventional AI and by DIAI, setting the semen in the middle of the uterine horn, but no significant differences between both the methods were found. Dalton et al. (1999) found that the fertilization of oocytes in the tubes was favored in bilateral DIAI, when the semen was deposited in the middle portion of the horn. Lopez-Gatius and Camon (1988) reported that the semen deposited near to the uterus-tubal junction, reduced the loss of sperm, improving the pregnancy rate by $10.3 \%$. Senger et al. (1988) reported good results with the bilateral DIAI, using half-dose of the semen placed deep into the two uterine horns, resulting in $44.7 \%$ in conventional AI against $64.7 \%$ in DIAI. According to Lopez-Gatius (2000), the greatest advantage of DIAI was related to its use by professionals, obtaining higher percentage on animal's pregnancy, since the number of sperm would be greatly reduced, e.g., in AI with sexed semen (Schenk et al. 2006; Borchersen and Peacock 2009; DeJarnette et al. 2009; Larson et al. 2010; Campanile et al. 2011).Verberckmoes et al. (2005) performed the AI with different quantities of frozen semen $(2,4,8$ to 12 million total sperm), setting the sperm into the body or in uterine horn, but no significant difference in the pregnancy rate was found. Anderson et al. (2004) reported that a concentration of two million total cells per insemination significantly affected the pregnancy rate, when the semen in the uterus body was deposited. Kurykin et al. (2006) showed tendency to increase the pregnancy rate after DIAI in the cows using two million of spermatozoa comparing the semen placement in the middle of the horn. Seidel Jr and Schenk (2008) compared bilateral DIAI (half dose in each uterine horn) versus the conventional AI (uterine body); the results very similar with a concentration of three million sexed sperm in relation to pregnancy rate $(44 \%$ in the uterine body and $43 \%$ in the uterine horn). In another experiment, a significant difference was observed in lactating Angus cows after bilateral AI in the uterine horns using three million spermatozoa compared with 20 million in the uterine body, resulting in $50 \%$ and $76 \%$ of pregnancy rate, respectively (Schenk and Seidel, 2007).

This study aimed to the compare pregnancy rate between the conventional AI and the DIAI using reduced spermatozoa concentration in beef cattle.

\section{MATERIAL AND METHODS}

This study was performed in Western of Parana State (Brazil). The body condition score ranging from 2.5 to 3.5 according Edmonson et al. (1989) (score 1=animal very thin and 5 obese). All the animals were submitted to identical management practices and the nutrition was composed by Brachiaria decumbens, and mineral supplementation ad libitum. The AI was performed by the same professional operator (veterinary) after observing the estrus, checking three times a day (morning, afternoon and evening). All the animals received an unique insemination with frozen bull semen from the same bull and batch. The average spermatozoa concentration was $4000000 \pm 486000$ per insemination. The animals were divided in two groups (G): G1 (135 cows) which were submitted to conventional artificial insemination (semen deposition in the uterine body) and G2 (135 animals) which received the deep intracornual artificial insemination (DIAI) in the same side where was located the dominant follicle by ultrasound examinations. The conventional AI and the DIAI was performed by a catheter $65.0 \mathrm{~cm}$ length (Minitub Co ${ }^{\circledR}$, Germany) by transcervical way. For DIAI, the catheter extremity was touched to be sure its deepest location by rectal palpation in the ipsilateral horn, where the dominant follicle was found by ultrasonography before the semen deposition. Pregnancy diagnosis was performed after 45 days of AI by ultrasound examination.

\section{Statistical analysis}

In order to verify the pregnancy rate between the conventional AI and the DIAI, the Fisher's exact test at the level of $p<0.01$ was carried out.

\section{RESULTS AND DISCUSSION}

The results are shown in Table 1. Lopez-Gatius and Camon (1988) reported that semen placed near to the uterus-tubal junction, reduced the loss of sperm and improved the pregnancy rate by $10.3 \%$, when compared with the deposition of semen in the uterine body. The present results showed $18.6 \%$ improvement in the pregnancy rate (Table 1) when DIAI was carried out. Senger et al. (1988) 
reported good results with the bilateral DIAI, using half-dose semen deposited deep into the two uterine horns, performing $44.7 \%$ in conventional AI against $64.7 \%$ in DIAI; similar results were obtained in this study. Hawk and Tanabe (1986) studying the pregnancy rate in the conventional AI and DIAI, placed the semen in the middle of the horn when no significant differences between the techniques were found. Later, Dalton et al. (1999) concluded that the fertilization of oocytes in the uterine tubes was improved in bilateral DIAI, compared to the semen deposition in the middle portion of the horn. Lopez-Gatius (2000) reported that the great advantage using the DIAI would be its use by the experimented people, resulting in a higher percentage of pregnancy rate in the cows, where the number of spermatozoa could be greatly reduced.

Table 1 - Pregnancy rate in Nellore cows submitted to deep intracornual artificial insemination (DIAI) and conventional artificial insemination (AI) with reduced spermatozoa concentration. $(n=270)$.

\begin{tabular}{cccc}
\hline Group & Total cows $(\mathrm{n})$ & Total pregnant $(\mathrm{n})$ & Pregnancy rate $(\%)$ \\
\hline DIAI & 135 & $91 / 135$ & $67,4^{\mathrm{a}}$ \\
AI & 135 & $66 / 135$ & $48,8^{\mathrm{b}}$ \\
\hline
\end{tabular}

Different letters in the same column indicates significance $(\mathrm{p}<0.01)$

Seidel Jr and Schenk (2008) compared bilateral DIAI (half dose in each uterine horn) versus the conventional AI (uterine body) and obtained very similar results with a concentration of three million sperm in relation to pregnancy rate $(44 \%$ in the uterine body and $43 \%$ in the uterine horn). In the present study, a higher level of pregnancy was achieved when the DIAI was used, probably due a higher number of sperm cells used in this experiment (four million spermatozoa). Verberckmoes et al. (2005) studied different quantity of frozen semen $(2,4,8$ to 12 million total spermatozoa), putting the sperm into the body or in the uterine horn, but no significant difference in the pregnancy rate were found. Anderson et al. (2004) found that a concentration of two million sperm cells significantly affected the pregnancy rate, when the semen in the uterus body was deposited. Kurykin et al. (2006) showed tendency to increase the pregnancy rate after DIAI in the cows using two million sperm compared to the deposition in the middle of the horn.

Besides the aspects already discussed, the DIAI technique could be considered as a promising tool for bovine and buffaloes reproduction using the sexed semen. The sexed semen is commercially produced and tested, and moreover contains small portions of sperm in a straw (about two million sperm) (Schenk et al. 2006; Borchersen and Peacock 2009; DeJarnette et al. 2009, Larson et al. 2010). That meant that the DIAI could be widely used by the producers. DIAI could also be explored in the protocols for ovarian superovulation in embryo collection (for embryo transfer) using the sexed semen (Schenk et al. 2006; Larson et al. 2010; Campanile et al. 2011), since farmer would have to choose between the male calves (for beef cattle) or female calves in dairy cattle (for milk) (Hohenboken 1999), according to the satisfaction of the producer's desire.

To conclude the present results showed a better pregnancy rate in DIAI in comparison to the conventional AI when reduced number of spermatozoa was used.

\section{REFERENCES}

Anderson M, Taponema J, Koskinem E, Dahlbom M. Effect of insemination with doses of 2 or 15 million frozen-thawed spermatozoa and semen deposition site on pregnancy rate in dairy cows. Theriogenology 2004; 61:1583-88.

Borchersen S, Peacock M. DanishAI field data with sexed semen. Theriogenolgy 2009; 71:59-83.

Campanile G, Gasparrini B, Vecchio D, Neglia G, Senatore EM, Bella A, et al. Pregnancy rates following AI with sexed semen in Mediterranean Italian buffalo heifers (Bubalus bubalis). Theriogenology 2011; 76:500-6.

Dalton JC, Nadir S, Bame JH, Saacke RG. Effect of a deep uterine insemination on spermatozoa accessibility to the ovum in cattle: a competitive insemination study. Theriogenology 1999; 51:883-90.

DeJarnette JM, Nebel RI, Marshall CE. Evaluating the success of sex-sorted semen in US dairy herds from on farm records. Theriogenology 2009; 71:48-58. 
Edmondson AJ, Lean IJ, Weaver LD, Farver T, Webster G. A body condition scoring chart for Holstein dairy cows. J Dairy Sci.1989; 72:68-78.

Hawk HW, Conley HH, Wall RJ, Whitaker RO. Fertilization rates in superovulating cows after deposition of semen on the infundibulum, near the uterotubal junction or after insemination with high number of sperm. Theriogenology 1983; 29:1131-43.

Hawk HW, Tanabe TY. Effect of unilateral cornual insemination upon fertilization rate in superovulating and single ovulating cattle. J Anim Sci. 1986; 63: 560-68.

Hohenboken WD. Application of sexed semen in cattle production. Theriogenology 1999; 52:1421-33.

Hunter RHF, Greve T. Deep uterine insemination in cattle: a fruitful way forward with small numbers of spermatozoa. Acta Vet Scan. 1998; 39:149-63.

Kurykin J, Jaakma U, Waldmann A, Jalakas M, Aidnik M, Majas L, Padrik P. Low semen dose intracornual insemination of cows at fixed time after PGF $2 \alpha$ treatment or at spontaneous estrus. Anim Reprod Sci. 2006; 95116-24.

Larson JE, Lamb GC, Funell BJ, Bird S, Martins A, Rodgers JC. Embryo production in superovulated Angus cows inseminated four times with sexed-sorted or conventional frozen-thawed semen. Theriogenology 2010; 73:698-703.

Larsson B, Larsson K. Distribution of spermatozoa in the genital tract of artificially inseminated heifers. Acta Vet Scan 1985; 26: 385-95.

López-Gatius F. Site of semen deposition in cattle: a review. Theriogenology 2000; 53:1407-14.
Lopez-Gatius F, Camon UJ. Increase of pregnancy rate in dairy cattle after preovulatory follicle palpation and deep cornual insemination. Theriogenology 1988; 29:1099-1103.

Nelson VE. Sperm discharge and distribution within the cow reproductive tract and after AI. J Anim Sci. 1987; 65:401.

Schenk JL, Seidel JR GE. Pregnancy rates in cattle with cryopreserved sexed spermatozoa: effects of laser intensity, staining conditions and catalase. Soc Reprod Fertil. 2007; 64: 165-77.

Schenk JL,Suh GE, Seidel Jr GE. Embryo production from superovulated cattle following inseminationmof sexed semen. Theriogenology 2006; 65:299-307.

Seidel JR GE, Schenk JL. Pregnancy rates in cattle with cryopreserved sexed sperm: Effects of sperm numbers per inseminate and site of sperm deposition. Anim Reprod Sci. 2008; 105:129-38.

Seidel Jr GE, Schenk JL, Herickhoff LA, Doyle SP, Brink Z, Green RD et al. Insemination of heifers with sexed sperm. Theriogenology 1999; 52:1407-20.

Senger PLP, Senger L, Becker WC, Davidge ST, Hillers JK. Reeves JJ. Influence of cornual insemination on conception in dairy cattle. J Anim Sci. 1988; 66: 3010-16.

Verberckmoes S, Soom AV, Dewulf J, Thys M, de Kruif AA. Low dose insemination in cattle with the Ghent device. Theriogenology 2005; 64:1716-28.

Received: March 01, 2011; Revised: July 13, 2011; Accepted: February 14, 2012. 